\title{
Improving employee performance using Innovative L\&D Interventions
}

\author{
Sangeeth Ibrahim \\ (BanasthaliVidyapith University, India)
}

\begin{abstract}
This study aims to present innovative practices in Learning and development which can help to improve employee performance in organizations leading to enhanced employee commitment and retention. As we all know, retention of valuable employees is a global challenge today. Organizations are constantly dueling with the task of retaining employees, and substantial evidence suggest that retention of skilled employees has become a serious concern to managers as they face ever increasing high rate of employee turnover (Arthur, 1994; Budhwar \& Mellahi, 2007). Scholars have clearly established the direct linkage between job satisfaction and organizational commitment on employee retention. (Budhwar \& Mellahi, 2007, Dole \& Schroeder, 2001). Various studies have proved that among other factors training and development opportunities can significantly enhance the organizational commitment and satisfaction of employees (Meyer \& Smith, 2000). It has been clearly found that if employees are given training and development opportunities, they will be more likely to remain in the environment. (Huselid, 1995).

Lisa Holden Rovers, CHRP in her study published in the e-Source for the Human Resources Institute of Alberta in May 2007 states that in-house learning strategies have a positive effect on engagement and retention. In house initiatives which are based on cost effective innovative ideas are identified to be valuable for businesses as they are seeking to embrace training and development opportunities in cost conscious manners. The author states that by engaging employees to share their knowledge, organizations can expect to increase the knowledge base of employees, control costs and retain talent.

Susan M Heathfield in her article in http://humanresources.about.com in 2007 cites opportunities for growth as a key factor in employee motivation and retention. This author states that apart from traditional classroom or blended learning approaches the following in house initiatives will enhance development.

- Involve employees in establishing goals, standards, priorities, and measurements.

- Assign employees to lead projects and teams.

- Assign employees to train other employees

- Provide learning materials on the Intranet, an internal company website.
\end{abstract}

Karen Shelton in her study titled "THE EFFECTS OF EMPLOYEE DEVELOPMENT PROGRAMS ON JOB SATISFACTION AND EMPLOYEE RETENTION" conducted at the University of Wisconsin-Stout in May 2001 asserts that Employee development programs clearly leads to employee satisfaction, which in turn leads to employee retention. People, who receive relevant and useful training, are generally happier in their jobs. When training is carried to the next level and becomes overall development, employees tend to feel even more valued by their employers. Organizations that provide employee development programs enjoy increased employee satisfaction and lower turnovers than those that do not.

Since it is imperative that employees are developed and grown, Organizations have to ensure that their Learning and Development initiatives are aligned with their Performance management methods. L\&Dinterventions must lead to performance improvements that can be measured and tracked by the Performance improvement systems. Otherwise there will be a disconnect between what is provided and what is expected. This will defeat the whole purpose and will lead to $L \& D$ interventions having no effect on performance improvements, rewards and recognitions, growth and thereby commitment, satisfaction and retention.

As an $L \& D$ specialist, the researcherhas seen such disconnects in many organizations that he has studied. Performance management systems have Competencies as their core. Many of the competency modelsadopted are very generic and doesn't reflect the specific requirements of the job to be performed. Moreover the interventions offered by $L \& D$ doesn't relate directly to these competencies. Hence theinterventions don't lead to improvements in areas that can be measured by performance management systems.

This study aims to provide solutions to this crucial problem. Based on the study of various organizations it proposes 6 innovative interventions that can bridge this gap between $L \& D$ offerings and Performance improvements as measured by Performance Management systems. The adoption of these interventions can lead to making $L \& D$ offerings more effective. They can provide a better linkagebetween interventions, development, growth, commitment and thereby retention. 
Keywords- Employee Retention, Performance Management, Learning and Development Interventions, Competencies, Employee Commitment

\section{Introduction}

This study attempts to provide solutions to the following critical questions that must be answered by Managers today.

- How can clear performance standards be established for each and every job function?

- How can these performance standards be made simple, easy to remember, inspiring and easy to follow?

- How can these standards be made measurable?

- How can the use of these standards be made a regular practice rather than an annual exercise?

- How can Learning and Development provide interventions to improve these competencies?

The researcher believes that the solution lies in the effective roll out of the following 6 Interventions

- Competency Standards

- The Competency Story

- Competency Champions

- Competency Best Practices

- Competency based Trainings

- The Competency campaign

These are simple easy to learn and easy to implement projects that can be embraced by all organizations. They can be easily customized to meet specific requirements. Hope this study will help organizations to improve the alignment and synergy between their performance management systems and Learning and Development Interventions which will in turn lead to more employee development, satisfaction and retention.

\section{Performance Management Systems}

For most Organizations, Performance Management is an inherent part of their Human Resources Management processes. Though the timing, the processes, the infrastructure and the forms portray the best of intentions namely Cascading the Organizational strategies into individual goals, creating visibility, ownership and responsibility for organizational objectives, setting up of proactive management practices, developing people along strategic capability requirements etc., most often than not there exists huge disconnects between what is intended and what is practiced.

PMS (Performance Management Systems) must be credited for providing good frameworks to measure performance. Performance is defined usually along two lines- Objectives in the form of SMART(Specific, Measurable, Aggressive, Realistic and Timed) Goals and Competencies derived from apt Competency models. Some Organizations also include a "Learning and development" component as well.

Though PMS systems require managers to discuss objectives and competencies with their staff at the beginning of the year and then review it at the middle and the end of the year, staff members are quiteoften unaware of their strengths and areas for improvement. While competency evaluations should make this possible and easy, they don't because of the following reasons.

- Most Competency models are very generic and don't include the specific Behavior, Knowledge, Skills and Attitudes required to meet individual objectives

- Competencies are not translated into simple observable behaviors that staff can identify with and take up easily

- Managers don't give specific feedback on Competency Improvements

- Training and Development functions don’t provide specific competency development interventions like training and coaching

- Improvements in Competency scores segmented along different functions, levels and other key considerations are seldom tracked at the Organization level.

Due to the above reasons, specific strengths are seldom tapped and critical areas for improvement are not addressed until they become unmanageable. In other words, its most often Performance measurement that is carried out, not performance management. Even in the case of Performance measurement, the methods adopted rarely provide clarity to the staff that is being assessed. Without clear awareness about what is expected from them and where they stand, staff does not take up the responsibility of developing themselves. Moreover this gap can lead to imperfect rewards and recognitionsprocesses which can leave a lot of employees dissatisfied and demotivated. Interactions with people during the study have revealed their lack of confidence in the performance management system. They opine that the system rarely provides opportunities to understand root causes of performance issues. It is widely said that these systems rarely go beyond mere annual rituals and doesn't foster useful and relevant development. This study recommends interventions that can address these critical gaps. 


\section{Competency Measurement}

Competence (or competency) is the ability of an individual to do a job effectively, leading to desired results. A competency is a set of observable behaviors that provide a framework for the identification, measurement and development of the performance of employees.The word "Competence "was introduced by Craig C. Lundberg in 1970 in his article "Planning the Executive Development Program". The concept was then taken up and popularized by several expertsincluding David Mcclelland who in 1973 published the paper titled "Testing for Competence Rather than for Intelligence". Most experts define competence as the sum total of Knowledge, Skills and Attitude that leads to behavior that delivers exceptional results.

This study doesn't attempt to get into discussing Competency models in detail. It however wants to focus on the inadequacies and short comings of the ways in which they are currently used in theOrganizations studied.

Most of the Organizations studied use Competency Models to define, identify, and manage performance of their employees. The majority of them use a two pronged approach which differentiates the Competencies that must be possessed by all their employees with the specific competencies that must be possessed by their managerial staff in particular. The former set of competencies titled CoreCompetencies/Basic competencies are behaviors that must be shown by all employees regardless of their function, seniority or level. Staff above a particular grade or occupying posts above a particular levelmust additionally show a set of competencies which are called Leadership/managerial competencies.

- Typical examples of Core Competencies

- Quality Orientation and Accuracy

- Communication Skills

- Team Orientation

- Initiative and commitment to achieve

- Customer Service and Relationship Orientation

- Typical examples of Leadership Competencies

- Decision Making

- Creative thinking

- Coaching

- Strategic Planning

In most organizations, each of these competencies is accompanied with a few statements or bullet points that translate the word into observable behaviors.

- For e.g. - Initiative and Commitment to achieve: Takes up improvement projects without being instructed to and strives to finish projects before the deadline.

- Coaching: Helps staff identify performance issues and gets them to take ownership to solve them.

When it comes to rating these competencies, most organizations use the below methodology.

- $1=$ Very poor

- $2=$ Average

- $3=$ Meets expectations

- $4=$ Exceeds expectations

- $5=$ Exceptional

The short comings of the above method can be summarized as below.

The observable behaviors provided are not specific to the job to be performed. Quality Orientation would mean different things and have different standards to a Bank teller, HR Manager, Auditor, Head of Operations, Security Guard and other professions. While all employees must strive to foster customer delight, behavior expected from front end personnel are different from those working at the back end. Communication skills required by the Sales person are different from that required by a mailing clerk. Adopting the generic approach without adopting it to meet the deliverables of each job can lead to ambiguity and thereby disengagement. And this can lead to inadequate development, dissatisfaction and poor retention. Unfortunately this issue exists in most of the organizations studied. Moreover the competencies and their translations are quite often cryptic and complexly worded which leads to lack of internalizing and interest on the part of the employees.

Interactions with people during studies conducted reveal that the lack of clarity leads to staff not focusing on the competencies. They opine that Managers rarely know how to clearly set and manage expectations and are also unable to coach and develop their employees. Thereby they consider the annual Performance Management process to be totally disconnected with their day to day activities and their performance requirements.

It is also opined that the lack of objectivity also leads to improper and unfair assessments and rewarding. Since there are no clear standards to differentiate exceptional performers, subjectivity creeps into the assessment process leading to dissatisfaction and grievances. 
1. Competency Standards

\section{The Proposed Interventions}

Each Competency must be translated into simple standards that are easy to remember, follow and measure. They should also sound inspiring. Standards can be created through brainstorming sessions involving stakeholders of each relevant function. They should ask the following questions.

- What does the competency, say "Quality Orientation and Accuracy" mean to us?

- What are the typical behaviors observed from a role model in this competency working in our area?

- What behaviors will lead to $100 \%$ quality orientation and accuracy in our area?

Once the behaviors are listed down, they can be converted into simple Positive self-talk statements. Scholars suggest that statements in this format motivate us subconsciously to follow them. These statements must be stated in positive and must be framed in present tense. Some examples of standards are given below.

- Quality Orientation and Accuracy for bank tellers: I always recount cash before handing it over.

- Quality Orientation and Accuracy for secretarial staff: I proof read letters before sending them out.

Create 3 to 5 standards for each competency for each functional area. You will thus have different standards for HR, Engineering, and Finance etc. for the same competency. Make sure that these standards are validated through multiple reviews conducted by staff from the respective functions. Try to make them as specific and relevant as possible.

Communicating the standards

As we are all aware that implementing change is not easy, we should go the extra mile to communicate the standards and ensure buy in from all quarters. Apart from email communications and poster campaigns, staff meetings must be arranged in the presence of the top management to present the standards. The benefits of adoption must be clearly explained to all staff. Managers must be motivated to speak and evangelize the standards to their respective staff. Most Organizations are going beyond conventional channels and are embracing the social media to communicate important messages. Having a Facebook page for the standards with the option of staff entering their feedback, acceptance and suggestions can really help in spreading the word. Some of the other effective methods that can be used are listed below.

- Publishing the standards on the desktops and screensavers

- Providing bookmarks, danglers and calendars with the standards

- Creating videos of staff, especially senior members repeating the standards

- Sending the standards as blackberry and twitter messages

- Repeatedly communicating the standards through email messages

- Having a mascot moving around the organization, spreading the message

- Making the standards a part of the employee handbook and induction training

The standards can be further simplified using Acronyms. By presenting the standards in an easy to remember format is key to its acceptance. One example is the GUEST Model that I facilitated for a bank.

- G: I always GREET the customer with a smile before he greets me

- U: I always UNDERSTAND the customers need by asking questions and listening well

- E: I always EXPLAIN the process, time frame and the costs involved to the customer

- S: I always SUGGEST alternate solutions to the customer

- T: I always thank the customer for giving me the opportunity to serve him

$\mathrm{U}$ sing a familiar word made it easy for the staff to remember the acronym. Having a word that epitomized customer service was an added bonus as well.

Incorporating the standards into the PMS system

The most important step would be to customize the performance appraisal forms to include the derived standards. Each function should have its own forms with the specific standards mentioned. This is a sure fire way to incorporate the new initiative into the corporate culture. Convincing the staff that the standards would be used to measure their performance which in turn effects their growth is an effective way to ensure quick buy in.

Key deliverables of each staff

The implementation of the standards provides another benefit as well. Every staff member becomes aware of his/her key deliverables. They realize their priority areas and understand that they need to focus on these deliverables irrespective of situational compulsions. They become aware of the significance of their contributions. Everyone wants to believe that they are doing meaningful work and that they are indeed making a difference. The standards instill this belief in them leading to more motivation and engagement.

\section{The Competency Story}

This is an innovative approach that was successfully implemented in one of the organizations studied. This is to recognize staff members who performed a competency in an exceptional manner. Whenever any staff member does such an exceptional act, another party in the organization can write a story about this performance and publish it through the portal. The project aims to recognize the staff member by publicizing his/her 
performance and also to motivate other employees to follow suit. A form is provided on the portal which solicits the following details

- Competency performed

- Name and details of the staff member who performed

- Details of behavior

- Effects on others/organization

This is sent to a team responsible for the project. They summarize the inputs into a story, and on a weekly basis publish these stories on the portal. The staff on whom the story was written and the staff who submitted the story are rewarded. There are standard rewards for each competency.

This project has received lot of support from the employees. Its serves to keep the competency standards live in the minds of the employees and the stories provide increasing clarity to them about the standards

\section{The Competency Champions}

This is a project that can be run for a particular period every year. In the organization that it was successfully implemented, each of the 5 Core competencies was taken up for a month. Announcements are made to the staff about the launch of the Competency champion's reward. The reward is given to staff that perform all the competency standards effectively. Using the forms made available on the portal, staff members can nominate themselves for the award. They should provide evidence for having followed the competency standards. Evidence could be in terms of project documents, appreciation emails, thank you letters, reports etc. The form must be endorsed by the respective managers and submitted online with the required supporting documents. The team running the awarding must then evaluate the submissions and check their alignment with the mentioned standards. Based on this evaluation the champions are selected. Champions are rewarded in grand ceremonies attended by the top management. To help other employees imbibe these behaviors, Interviews are conducted with the champions, their peers and their managers and these interviews are published online.

\section{Competency Best Practices}

While the Competency Champions focus on individuals, the Best Practiceinterventions focus on Managers and Departments. The onus is on managers to initiate approaches that would improve the competencies of their staff. This project solicits such projects implemented by managers/departments. Some of the examples of such projects implemented are

- Quality Orientation and Accuracy: Creating posters of checklists and work break downs. Simplifying policy and procedure documents

- Customer Service and Relationship Orientation: Conducting customer survey and feedback

- Team Orientation: Conduction family get together sessions

- Initiative and Commitment to achieve: setting up of suggestion schemes and quality circles It is evident that when managers implement such projects, the competencies of staff improve as the critical behaviors required to excel in these competencies must be shown during the implementation of these projects.

The Competency Best Practices intervention aims to collect these projectsanalyze and reward them and also share it with the rest of the Organization. The selected practices are honored in the presence of the top management and then shared through eLearning modules and presentations.

\section{Competency based trainings}

This involves the restructuring of the training courses to match the Competencies in the Performance management system. Instead of providing a long list of courses that doesn't relate to the PMS system, courses that teach or reinforce behaviors related to the standards must be provided. Hence the training calendar will have courses on Quality Orientation and accuracy, Initiative and commitment to achieve and other competencies. Instead of making these courses optional, all associates who scored poorly or below par on these competencies in the previous PMS cycle must be asked to compulsorily take these courses.

These courses cannot be delivered without customization. The biggest challenge would be to negotiate with the training service providers to provide customized courses that emphasize your competency standards. Each course must facilitate a process wherein each attendee is coached on the standard that he is weak in. The Trainees must be provided the tools to improve these standards and the training must also include a process where the trainee must agree to demonstrate the standard through action plans that can be supported by managers and peers. 
6. Competency Campaign

All the above interventions namely creation and communication of standards, competency story, competency champion, best practices and competency trainings can be delivered through a recurring annual campaign. Each competency can be accorded a particular time period. The campaign must run between the launch and the end of the performance management process. This will help to keep the competencies and their related interventions visible, talked about and accepted.

\section{Conclusion}

From experience, the researcher has found that the above 6 interventions can help organizations find answers to the questions that we presented in the section "Introduction". Though they are simple and easily replicable, organizations must take efforts to customize them to meet unique organizational requirements. Their effects must me measured by analyzing the improvements in the Competency scores ascertained during performance appraisals. Targets for competency improvements must be set at the beginning of each year. Each intervention must be improved base on the improvements in the scores that they fostered. In addition to this, perception measures and the acceptance level of the campaign measured through number of submissions for champions and best practices can be used to make improvements. By continuously measuring the effectiveness and making improvements, these interventions can bring about performance improvements which will help the organization meet its business objectives through committed, competent and confident staff who will willingly remain engaged.

\section{Acknowledgements}

To God, My supervisor-Dr.HarshPurohitand my family.

\section{Articles, Proceedings and Books}

\section{References}

[1] Arthur, J. (1994). Effects of human resource systems on manufacturing performance and turnover. Academy of Management Journal, 37(3), 670-687.

[2] Budhwar, P., \& Mellahi, K. (2006). Managing human resources in the Middle East. Oxon: Psychology Press.

[3] Dole, C., \& Schroeder, R. (2001). The impact of various factors on the personality, job satisfaction and turnover intentions of professional accountants. Managerial Auditing Journal, 16(4), 234-245.

[4] Meyer, J., \& Smith, C. (2000). HRM practices and organizational commitment: Test of a mediation model. Canadian Journal of Administrative Sciences, 17(4), 319-331.

[5] Huselid, M. (1995). The impact of human resource management practices on turnover, productivity, and corporate financial performance. Academy of Management Journal, 38(3), 635-672.

[6] Lisa Holden Rovers, CHRP, e-Source for the Human Resources Institute of Alberta , May 2007

[7] Susan M Heathfield, http://humanresources.about.com, 2007

[8] Karen Shelton, "THE EFFECTS OF EMPLOYEE DEVELOPMENT PROGRAMS ON JOB SATISFACTION AND EMPLOYEE RETENTION", University of Wisconsin-Stout, May 2001 